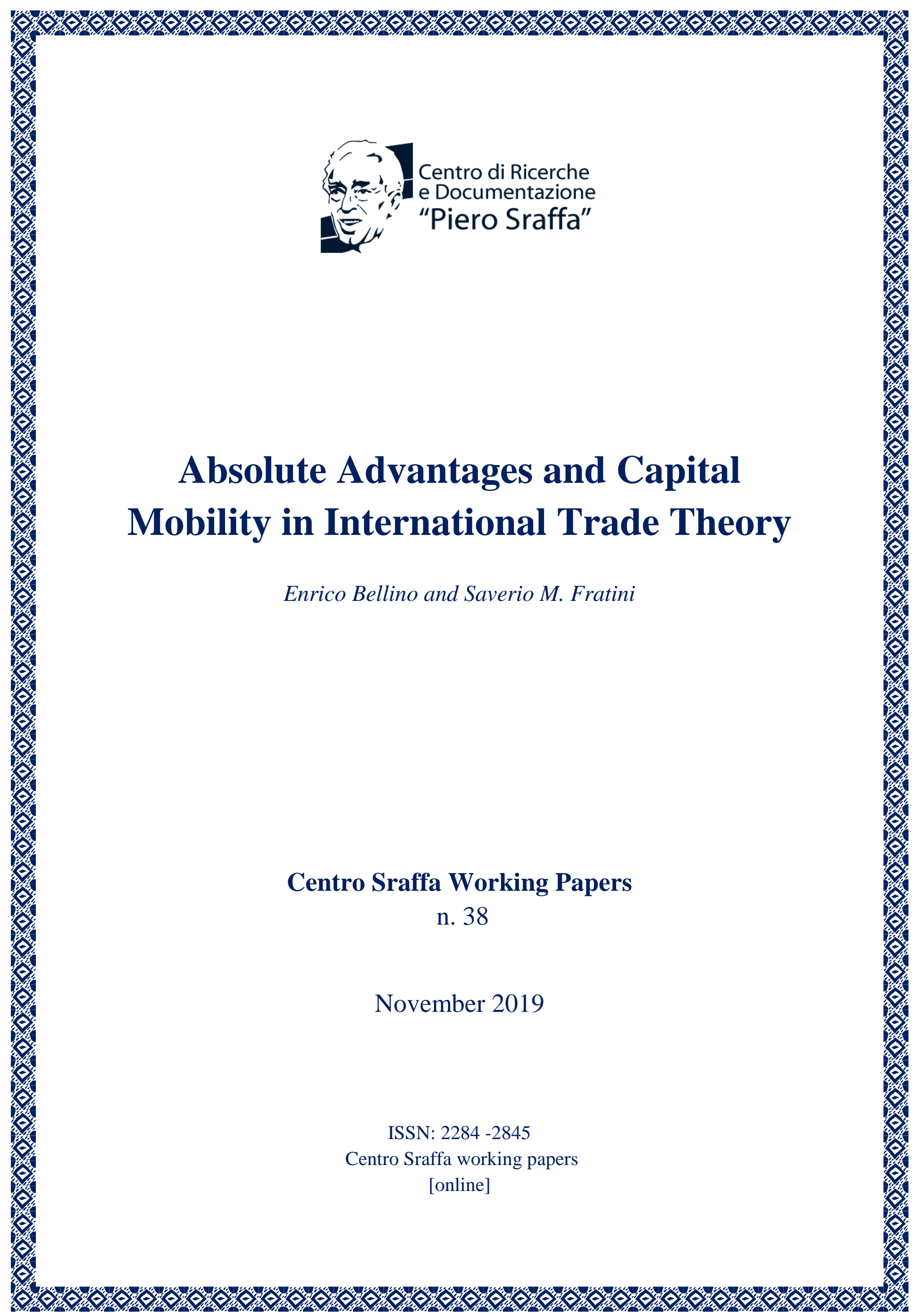




\title{
Absolute Advantages and Capital Mobility in International Trade Theory
}

\author{
Enrico Bellino $^{(\text {a) }} \&$ Saverio M. Fratini ${ }^{(\mathrm{b})}$ \\ (a) Catholic University of the Sacred Heart \\ (b) Roma Tre University
}

\begin{abstract}
In this paper we will focus upon the role of absolute advantages in international specialization in connection with the phenomenon of capital mobility. We will provide a historical and analytical reconstruction of the main contributions, starting from the contrast between Smith's and Ricardo's standpoint on the issue. Two deep-rooted conclusions will be questioned by the analysis of this literature: (a) the unequivocal mutual benefits of opening up to international trade; and (b) the specialization of each country in the production of at least one good. With regard to this point, we will also provide a generalization of a result obtained by Parrinello (2010).
\end{abstract}

Keywords: capital mobility; absolute advantage; specialization.

JEL codes: B51; D24; F21.

\section{Introduction ${ }^{1}$}

According to Adam Smith and David Ricardo, all the countries involved can gain from international trade. International trade is mutually beneficial. This thesis has been recently challenged by some scholars who maintained that the idea of 'national competitiveness' - due to absolute advantage in production of commodities - can make sense in a global economy (for a survey, see Parrinello, 2010).

Here we will discuss the relevance of the notion of absolute advantage in the analysis of international trade, trying to keep together both the point of view of the history of economic thought and the theoretical one. We shall start (section 2) from Adam Smith's idea that the international division of labour has beneficial effects for every country involved. Then Ricardo reformulated the idea of gain from trade by means of his theory of

\footnotetext{
${ }^{1}$ For comments and suggestions, thanks are due to Aldo Barba, Roberto Ciccone, Fabio Freitas, Christian Gehrke, Sergio Parrinello, Fabio Petri and Neri Salvadori. Needless to say, the usual caveat applies.
} 
comparative advantage. We will highlight that the theory of comparative advantage is grounded on the assumption that capital cannot be freely moved across countries. Removing this assumption opens the door to different analyses and results.

Emmanuel, in his book on 'unequal exchange' (Emmanuel, 1972), introduces us into a critical view about the benefits arising from international trade for the countries involved. As we shall see (section 3), he showed that the country that exports the commodity produced by the higher organic composition industry will enjoy a transfer of value in its favour from the other country. Emmanuel's argument was - at least initially grounded on Marx's mechanism of transformation of values into prices of production. A few years later, Gibson (1980) tried to put it on a more solid base by expressing commodity prices in terms of Sraffa's equations (section 4).

Although the possibility of exclusion of one country from the international specialization of production was implicit in Gibson's analytical framework, he was not able to grasp it. This case was instead explicitly addressed by Brewer (1985). By means of a two-country model in which unassisted labour is the sole input of production, he showed the theoretical possibility that capitalists - in order to maximize the rate of profit - want to invest their capital in one country only (section 5).

Parrinello (2010) returned to investigate international specialization and the possible tendency to desertification in terms of choice of techniques in a circular production framework with one capital good and one consumption good (section 6). We will provide (section 7) a generalization of Parrinello's analysis for the case with many commodities.

\section{The rise of comparative advantage theory}

It is widely acknowledged that Adam Smith's foreign trade theory reflects his ideas about the division of labour and economic growth. In his view, the main benefit of international trade comes from the increase in productivity that the international division of labour makes possible (see Aspromourgos, 2008, pp. 137-8). Accordingly, he is fundamentally in favour of free trade since he thinks that there are, in general, beneficial effects for all countries involved. Because of free trade, even a country with a deficit in the commercial balance can have an increase in its domestic income due to the increase in productivity resulting from the international division of labour. ${ }^{2}$

\footnotetext{
${ }^{2}$ As Smith remarks:
}

Nothing, however, can be more absurd than this whole doctrine of the balance of trade, upon which, not only these restraints, but almost all the other regulations of commerce are founded. When two places trade with one another, this doctrine supposes that, if the balance be even, neither of them either loses or gains; but if it leans in any degree to one side, that one of them loses, and the other gains in proportion to its declension from the exact equilibrium. Both suppositions are false. A trade which is forced by means of bounties and monopolies, may be, and commonly is disadvantageous to the country in whose favour it is meant to be established [...]. But that trade which, without force or constraint, is naturally and regularly carried on between any two places, is always advantageous, though not always equally so, to both.

By advantage or gain, I understand, not the increase of the quantity of gold and silver, but that of the exchangeable value of the annual produce of the land and labour of the country, or the increase of the annual revenue of its inhabitants (1976, p. 488-9). 
In Smith's analysis, foreign trade is closely connected with capitalists' investment decisions (1976, pp. 368-71). Capitalists do not employ their capital in the production of a commodity that can be imported at a smaller cost:

If a foreign country can supply us with a commodity cheaper than we ourselves can make it, better buy it of them with some part of the produce of our own industry, employed in a way in which we have some advantage. The general industry of the country, being always in proportion to the capital which employs it, will not thereby be diminished [...]; but only left to find out the way in which it can be employed with the greatest advantage. It is certainly not employed to the greatest advantage, when it is thus directed towards an object which it can buy cheaper than it can make (Smith, 1976, p. 457).

Within this framework, the decision to import commodities from abroad by trading them for domestic ones does not seem different from any other decision about the employment of capital in different activities. The choice between making a commodity at home or buying it from abroad seems to be of the same nature as the one between alternative methods of production. First, the leading principle is the search for the highest rate of return. Second, absolute costs - and not just the comparative ones - seem relevant. ${ }^{3}$

The predominance of the notion of comparative costs in the explanation of the international specialization of production appears later, thanks to the contribution of Ricardo.

\subsection{Ricardo and the relevance of comparative costs}

Ricardo takes up Adam Smith's idea that all the countries involved make a gain from international trade. However, in his view, the gain does not arise as a result of the international division of labour, namely because of the technical progress. The gain concerns the quantity of commodities made available, given the employment of labour and the technical conditions of production.

We will recall here Ricardo's standpoint by his very well-known two-commodity, twocountry numerical example. The commodities considered are wine and cloth; the countries are England and Portugal. Every year, England imports wine from Portugal, trading it for cloth. Ricardo intends to show that both England and Portugal have a gain from this trade. $^{4}$

Let us define one unit of wine as the (given) quantity of this commodity that England buys from Portugal and, similarly, one unit of cloth is the quantity that Portugal purchases

\footnotetext{
${ }^{3}$ Actually, in Adam Smith's analysis there is a certain ambiguity about this point. On the one hand, there is no doubt that the international division of labour - i.e. international specialization - is seen as a costminimizing solution and, accordingly, absolute costs are relevant. On the other, there are passages in which Smith seems to refer to comparative costs. In particular, discussing the advantages of foreign trade, Smith writes that the domestic production of the commodities purchased from abroad would have required the employment of a capital (cost) greater than that necessary to produce the commodities that are exported in exchange for them (1976, p. 457), and this argument seems to be close to a reasoning based on comparative costs.

${ }^{4}$ In his argument, Ricardo assumes that trade between England and Portugal already exists and a given quantity of English cloth is exchanged for a given quantity of Portuguese wine. What he wants to prove is that both countries have gains. In particular, he intends to prove that Portugal has a gain in importing cloth that is produced in England with a greater quantity of labour than in its domestic industry.
} 
from England. Once these units of measure for the two commodities are adopted, the relative price of wine in terms of cloth is, by definition, $p=1$.

Following Ricardo, both commodities are assumed to be produced with unassisted labour with the methods of production described in Table 1.

\begin{tabular}{|c|c|}
\hline Portugal & England \\
\hline 80 units of labour $\rightarrow 1$ unit of wine & 120 units of labour $\rightarrow 1$ unit of wine \\
90 units of labour $\rightarrow 1$ unit of cloth & 100 units of labour $\rightarrow 1$ unit of cloth \\
\hline
\end{tabular}

Table 1 - Technical coefficients of production.

With a quantity of wine produced by means of 80 units of labour, Portugal obtains a quantity of cloth whose production would have required the employment of 90 units of labour. Similarly, with a quantity of cloth produced by means of 100 units of labour, England obtains a quantity of wine whose domestic production would have required the employment of 120 units of labour. Both the countries have thus a gain from trade.

More precisely, with the numbers of Ricardo's example, notwithstanding Portugal has lower absolute costs on both the sectors compared to England, it has a gain from importing cloth from England. The conclusion is that the existence of gains from trade depends on comparative costs and not on absolute costs..$^{5}$ This is the main achievement of $\mathrm{Ri}$ cardo's theory of international trade:

Though she [Portugal] could make the cloth with the labour of 90 men, she would import it from a country where it required the labour of 100 men to produce it, because it would be advantageous to her rather to employ her capital in the production of wine, for which she would obtain more cloth from England, than she could produce by diverting a portion of her capital from the cultivation of vines to the manufacture of cloth (Ricardo, Works I, p. 135).

\subsection{Mobility (or immobility) of capital}

As Ricardo himself explicitly recognizes, his theory of international trade is grounded on the assumption that capital cannot be easily moved from one country to another. ${ }^{6}$ This is, in his view, the main difference between domestic and international trade:

Thus England would give the produce of the labour of 100 men, for the produce of the labour of 80. Such an exchange could not take place between the individuals of the same country. The labour of 100 Englishmen cannot be given for that of 80 Englishmen, but the produce of the labour of 100 Englishmen may be given for the produce of the labour of 80 Portuguese, 60 Russians, or 120 East Indians. The difference in this respect, between a single country and many, is easily accounted for, by considering the difficulty

\footnotetext{
${ }^{5}$ However, the size of the gains - determined on the basis of the quantities of commodities obtained with a given employment of labour (and capital) - in the two countries depends, clearly, on absolute costs.

${ }^{6}$ On the relevance of the assumption that capital cannot be moved across counties for Ricardo's theory of international trade, see also Montani (2008) pp. 90-91.
} 
with which capital moves from one country to another, to seek a more profitable employ$m e n t$, and the activity with which it invariably passes from one province to another in the same country [Ricardo, Works I, pp. 135-6, (Emphasis added)].

Ricardo notes that, with the numbers used in his example, English capitalists would obtain a higher rate of profit investing their capital in Portugal rather than in the production of cloth in England. In fact, the amount of output that in England requires an investment of capital corresponding to the wages for 100 units of labour, in Portugal can be obtained with a capital corresponding to the wages for 90 units of labour. ${ }^{7}$ However, he adds that, according to his experience, capitalists prefer a low rate of profit in their own country rather than investing abroad, since they fear losing control of their capital:

Experience, however, shews, that the fancied or real insecurity of capital, when not under the immediate control of its owner, together with the natural disinclination which every man has to quit the country of his birth and connexions, and intrust himself with all his habits fixed, to a strange government and new laws, check the emigration of capital. These feelings, which I should be sorry to see weakened, induce most men of property to be satisfied with a low rate of profits in their own country, rather than seek a more advantageous employment for their wealth in foreign nations (Ricardo, Works I, pp. 136-7).

In this respect, Smith's standpoint significantly differs from that of Ricardo. According to Adam Smith, although 'every individual endeavours to employ his capital as near home as he can' when he can obtain the same rate of profit (see Smith, 1976, p. 454), capitalists tend to move their capital abroad if they foresee a more profitable employment. Talking about the taxes upon profit, he says that the capitalist is 'a citizen of the world':

The proprietor of land is necessarily a citizen of the particular country in which his estate lies. The proprietor of stock is properly a citizen of the world, and is not necessarily attached to any particular country. He would be apt to abandon the country in which he was exposed to a vexatious inquisition, in order to be assessed to a burdensome tax, and would remove his stock to some other country where he could, either carry on his business, or enjoy his fortune more at his ease (Smith, 1976, p. 848-9).

That could maybe explain why Smith - differently from Ricardo - does not attach much importance to comparative costs.

\subsection{Money prices and trade}

While the comparative cost theory is based on relative prices, the decisions of consumers and producers to purchase domestic or foreign commodities are based on monetary prices and the exchange rate. In particular, in Ricardo's times, the exchange rate between currencies was the result of their parity with respect to gold: each currency corresponded to a certain quantity of gold and the exchange rate was the ratio between them. Moreover, since gold was the actual means of payment, its distribution across the countries and, accordingly, its value in each of them are affected by the international trade.

In this respect, Ricardo writes:

\footnotetext{
${ }^{7}$ In this argument, Ricardo seems to implicitly assume that there is the same (real) wage rate in both countries.
} 
Gold and silver having been chosen for the general medium of circulation, they are, by the competition of commerce, distributed in such proportions amongst the different countries of the world, as to accommodate themselves to the natural traffic which would take place if no such metals existed, and the trade between countries were purely a trade of barter.

Thus, cloth cannot be imported into Portugal, unless it sell there for more gold than it cost in the country from which it was imported; and wine cannot be imported into England, unless it will sell for more there than it cost in Portugal (Ricardo, Works I, p. 137).

In order to reconstruct Ricardo's argument,${ }^{8}$ let us start by introducing commodity prices in terms of gold in the two countries. They are determined by the quantities of labour employed times the wage rate in terms of gold. The latter is the amount of gold necessary to buy a given basket of wage goods ${ }^{9}$ and, accordingly, it depends on the purchasing power of gold, which in turn, in Ricardo's theory, is related to the available quantity of gold in the country.

Hence, let $G_{P}$ and $G_{E}$ be the quantities of gold available in Portugal and England respectively, the gold wage rates in Portugal and England are $W_{P}\left(G_{P}\right)$ and $W_{E}\left(G_{E}\right)$. Commodity prices in terms of gold are then determined as follows:

$$
\begin{gathered}
\text { Portugal } \\
P_{w}^{P}=80 \cdot W_{P}\left(G_{P}\right) \cdot\left(1+r_{P}\right) \\
P_{c}^{P}=90 \cdot W_{P}\left(G_{P}\right) \cdot\left(1+r_{P}\right) \\
\quad \text { England } \\
P_{w}^{E}=120 \cdot W_{E}\left(G_{E}\right) \cdot\left(1+r_{E}\right) \\
P_{c}^{E}=100 \cdot W_{E}\left(G_{E}\right) \cdot\left(1+r_{E}\right)
\end{gathered}
$$

In the price equations above, $P_{i}^{J}$ is the gold price of commodity $i$ in country $J$, with $i=w$, $c$ and $J=P, E$, whereas $r_{J}$ is the rate of profit in country $J$. The latter, according to Ricardo's theory, depends on the quantity of labour embodied in the physical wage rate. ${ }^{10}$

Now, given an arbitrary initial distribution of gold among the two countries, following Ricardo's example (see Ricardo, Works I, p. 137-8) it can happen that $P_{w}^{P}>P_{w}^{E}$ and $P_{c}^{P}>$ $P_{c}^{E}$. In this event, consumers and producers of both countries have an advantage in buying both commodities in England. As a result, the quantity of gold $G_{P}$ decreases and $G_{E}$ increases. The purchasing power of gold in Portugal increases and so $W_{P}\left(G_{P}\right)$ falls. In England, instead, the purchasing power of gold decreases and $W_{E}\left(G_{E}\right)$ must rise.

The need to move gold from one country to another in payment for imported commodities ceases when the value of the commodity imported, in terms of gold, is exactly equal

\footnotetext{
${ }^{8}$ For a different reconstruction, cf. Shaihk (1980, pp. 214-6). In Shaihk's argument, the level of prices in terms of gold does not derive from the money wage rate, but from attributing to Ricardo an ante litteram version of Fisher's exchange equation: $M V=P T$. We believe that our reconstruction is closer to Ricardo's original ideas.

${ }^{9}$ For the sake of simplicity, we can here assume that wine and cloth are not included into the wage goods. This assumption - which can be dropped at the cost of some formal complications - does not alter the conclusion we shall arrive at by means of our reconstruction of Ricardo's analysis.

${ }^{10}$ As is known, according to Ricardo's theory of profit, let $\omega$ be the quantity of labour embodied in the wage rate, then $r=1 / \omega-1$.
} 
to that of the commodity exported, namely: $P_{w}^{P}=P_{c}^{E}$ or $P_{w}^{P} / P_{c}^{E}=p=1 .{ }^{11} \mathrm{In}$ other words, following Ricardo's argument, the distribution of gold among countries tends toward a combination $\left(G_{P}^{*}, G_{E}^{*}\right)$ such that:

$$
\frac{80 \cdot W_{P}\left(G_{P}^{*}\right) \cdot\left(1+r_{P}\right)}{100 \cdot W_{E}\left(G_{E}^{*}\right) \cdot\left(1+r_{E}\right)}=1
$$

Once this distribution is realized, the trade between countries is like a 'pure trade of barter', as Ricardo writes.

Finally, as can be easily proved, if the distribution of gold is $\left(G_{P}^{*}, G_{E}^{*}\right)$, then $P_{w}^{P}<P_{w}^{E}$ and $P_{c}^{P}>P_{c}^{E} .^{12}$ In fact:

$$
\frac{80 \cdot W_{P}\left(G_{P}^{*}\right) \cdot\left(1+r_{P}\right)}{90 \cdot W_{P}\left(G_{P}^{*}\right) \cdot\left(1+r_{P}\right)}<\frac{80 \cdot W_{P}\left(G_{P}^{*}\right) \cdot\left(1+r_{P}\right)}{100 \cdot W_{E}\left(G_{E}^{*}\right) \cdot\left(1+r_{E}\right)}=1<\frac{120 \cdot W_{E}\left(G_{E}^{*}\right) \cdot\left(1+r_{E}\right)}{100 \cdot W_{E}\left(G_{E}^{*}\right) \cdot\left(1+r_{E}\right)}
$$

\section{Emmanuel and the 'unequal exchange'}

As seen in the previous section, according to Smith, capitalists are 'citizens of the world': they tend to move their capital abroad if, in so doing, they can earn more. By contrast, in Ricardo's analysis of foreign trade, English capitalists, because of 'fancied or real insecurity', prefer to invest their capital in domestic production, although the investment in Portugal is assumed to yield a higher rate of profit.

Ricardo's view about the relevance of comparative costs has characterized the mainstream literature on foreign trade grounded on comparative costs until today, with some exceptions, whereas Smith's standpoint on capital mobility was adopted in alternative analyses of international specialization and trade. One of the most significant contributions in this approach was provided by Arghiri Emmanuel in his book Unequal Exchange: A Study of the Imperialism of Trade (Emmanuel, 1972).

Emmanuel assumes that there are two countries of regions: 'centre' and 'periphery'. The real wage rate - which depends on social and institutional elements - is fixed and different by country. By contrast, a uniform rate of profit across countries tends to arise because capital is freely mobile. Capitalists' desire to invest in the country where the rate of profit is higher generates a process of change in the quantities produced, which only stops when the profit rate is the same in each sector and in each country.

With reference to a closed economy, this mechanism had already been studied by classical economists and by Marx. Emmanuel, in his book, tries to use Marx's argument on

\footnotetext{
${ }^{11}$ In the process we are considering, the shifting of gold from Portugal to England leads to an increase in the $W_{E} / W_{P}$ ratio. This increase in the $W_{E} / W_{P}$ ratio comes to a stop when the trade balance in the two countries is even. Given that $80 / 100<120 / 90$, we are sure that, in the rest position of this process, Portugal exports wine and England cloth.

12 The definition of the physical unit of both commodities as the quantities exchanged between England and Portugal enables us to avoid the objection raised by Parrinello, who maintained that: '[c]ontrary to a common interpretation ... in Ricardo's example it is not implicit that the term of trade between cloth and wine is equal (1:1)' (Parrinello, 1988, p. 587).
} 
the transformation of values into prices of production and the tendency toward a uniform rate of profit, in order to maintain that international trade entails a transfer of surplus value from the 'periphery' to the 'centre'.

According to Marx's analysis, if the rate of profit must be uniform across productive sectors, then commodities cannot be traded at (relative) prices corresponding to their (relative) values, i.e. the amounts of direct and indirect labour they embody. For instance, let us assume that one unit of commodity $i$ embodies a quantity of direct and indirect labour $\ell_{i}+c_{i}$. In Marxian terms, $c_{i}$ is the amount of constant capital $-i$.e. the amount of labour embodied in the capital goods - per unit of output, while $\ell_{i}$ can be decomposed in variable capital $v_{i}$-i.e. the amount of labour embodied in the wages for $\ell_{i}$ units of labour - and surplus value, with $s_{i}=\ell_{i}-v_{i}$. Assuming that workers receive the same wage rate in every sector, the rate of surplus value $s_{i} / v_{i}$ is uniform. That implies that capitals of different organic composition $c_{i} / v_{i}$ produce different amounts of surplus value, $s_{i}$, per unit of total capital invested, $c_{i}+v_{i}$.

Assume there are two commodities, namely 1 and $2 ; c_{1} / v_{1}>c_{2} / v_{2}$ implies $s_{1} /\left(c_{1}+v_{1}\right)$ $<s_{2} /\left(c_{2}+v_{2}\right)$. In this case, the equality of the rate of profit in the two sectors needs a redistribution of surplus value from the sectors with a low organic composition of capital (OCC) toward the ones with a high OCC - i.e. from sector 2 to sector 1 . In fact, this is exactly the role played by prices of production. Let $r$ be the general rate of profit, $p_{i}=\left(c_{i}\right.$ $\left.+v_{i}\right)(1+r)$. Hence, since the production of commodity 1 has an OCC higher than the average one, then its price of production must be higher than its value, namely $p_{1}>c_{1}+$ $v_{1}+s_{1} .{ }^{13}$ Symmetrically, $p_{2}<c_{2}+v_{2}+s_{2}$. In this way, the sector with a higher than average OCC intercepts surplus-value 'extracted' in the sector with a lower OCC.

In Emmanuel's view, a similar transfer of surplus value takes place between countries due to the foreign trade. In particular, Emmanuel distinguishes between two forms of unequal exchange: one in the broad sense and another in the strict sense. The former is a mere extension to international trade of the case just considered. The wage rate is assumed to be uniform in the two countries, so that they have the same rate of surplus value. International specialization is exogenously given, and the central country is assumed to produce commodity 1 , whose process employs the highest OCC, while the peripheral country has a specialization in the production of commodity 2 . Hence, if capital is mobile enough to lead toward a situation with a uniform rate of profit across countries, then commodity 1 is sold at an international relative price higher than its relative value and, accordingly, a certain amount of surplus value is moved from the periphery toward the centre.

The unequal exchange in the strict sense is grounded on the assumption that the rate of surplus value in the periphery is higher than the rate in the centre due to different wage rates. Keeping the assumption that the central country is specialized in the production of commodity 1 and the periphery in the production of commodity 2, we have $c_{1} / v_{1}>c_{2} / v_{2}$, as in the previous case, but also $s_{1} / v_{1}<s_{2} / v_{2}$. Hence, a larger transfer of surplus value from the periphery to the centre is needed in order to make the rate of profit uniform

\footnotetext{
${ }^{13}$ This can be very easily proved. Since the OCC in sector 1 is greater than the average, then $s_{1} /\left(c_{1}+v_{1}\right)$ $<r$ or, in other terms, $s_{1}<\left(c_{1}+v_{1}\right) r$. Accordingly, $c_{1}+v_{1}+s_{1}<\left(c_{1}+v_{1}\right)(1+r)$.

Symmetrically, $c_{2}+v_{2}+s_{2}>\left(c_{2}+v_{2}\right)(1+r)$.
} 
across countries. Accordingly, in the case of unequal exchange in the strict sense, the international relative price of commodity 1 is higher than both its relative value and the relative price it would have been in a closed economy.

Moreover, considering the amount of surplus value obtained as the source of capital accumulation, Emmanuel maintained that, in the event of unequal exchange in the strict sense, capital accumulation tends to be faster in the central country, which has the highest wage rate, than in the peripheral one, which has instead the lowest wage rate. This is a rather surprising result due to the fact that, in this case, periphery does not have a higher rate of profit notwithstanding it has a lower wage rate than the centre.

Finally, although Emmanuel put his thesis in terms of Marxian concepts - such as: rate of surplus value, organic composition of capital and prices of production - to the extent the point concerns a deviation of international prices from those prevailing in a closed economy, it can also be reformulated by means of Sraffa's price theory. In fact, Emmanuel himself went along this path after the publication of his book, but a further step in this direction was taken by Bill Gibson (1980).

\section{Unequal exchange in Gibson's reformulation}

In his article of 1980, Gibson reformulated Emmanuel's argument about unequal exchange, introducing two elements of novelty: i) domestic and international prices are determined by means of Sraffa's equations; ii) country specialization is not exogenously given - as in Emmanuel's analysis - but endogenously determined.

In his basic model, Gibson assumes there are two commodities, 1 and 2 as before, and two regions or countries: A and B. Country A is the centre, it is the high-wage region; while country $B$ is the peripheral and low-wage region.

In each country, the real wage rate is given in physical terms, as 'the food for the cattle or the fuel for the engine'. Precisely, $w_{j}^{X}$ denotes the quantity of commodity $j(j=1,2)$ that enters into the physical wage rate in country $X(X=A, B)$. By assumption, the wage rate in country $\mathrm{A}$ must be greater than the wage rate in country $\mathrm{B}$, namely: $w_{1}^{A} \geq w_{1}^{B}$, $w_{2}^{A} \geq w_{2}^{B}$ and at least one of these inequalities must be strict.

As for technical conditions, assuming that wages are paid at the beginning of the production process, once the wage rates in the two countries are specified physically, we can refer to 'socio-technical' coefficients of production. Let $a_{i j}^{X}$ and $\ell_{i}^{X}$ denote the quantities of commodity $j$ and labour employed, in country $X(X=A, B)$, in order to produce 1 unit of commodity $i(i=1,2)$; then $\tilde{a}_{i j}^{X}=a_{i j}^{X}+\ell_{i}^{X} w_{j}^{X}$ represents the quantity of commodity $j$ employed as both capital good and wage good, in country $X$, in order to produce 1 unit of commodity $i$. 


\begin{tabular}{|c|c|}
\hline Country A & Country B \\
\hline$\tilde{a}_{11}^{A} \oplus \tilde{a}_{12}^{A} \rightarrow 1$ unit of commodity 1 & $\tilde{a}_{11}^{B} \oplus \tilde{a}_{12}^{B} \rightarrow 1$ unit of commodity 1 \\
$\tilde{a}_{21}^{A} \oplus \tilde{a}_{22}^{A} \rightarrow 1$ unit of commodity 2 & $\tilde{a}_{21}^{B} \oplus \tilde{a}_{22}^{B} \rightarrow 1$ unit of commodity 2 \\
\hline
\end{tabular}

Table 2 - Socio-technical coefficients of production.

Let $p$ and $r$ be the price of commodity 1 in terms of commodity 2 and the rate of profit, respectively. International trade and capital mobility entail that each of these magnitudes must be at the same level in both the countries. These levels, however, depend on the international specialization of production, which, as said, is endogenously determined in Gibson's analysis.

Following Gibson's argument, let us start from the price equations of the two commodities in the two countries:

$$
\begin{aligned}
& (1+r)\left(\tilde{a}_{11}^{A} p+\tilde{a}_{12}^{A}\right)=p \\
& (1+r)\left(\tilde{a}_{21}^{A} p+\tilde{a}_{22}^{A}\right)=1 \\
& (1+r)\left(\tilde{a}_{11}^{B} p+\tilde{a}_{12}^{B}\right)=p \\
& (1+r)\left(\tilde{a}_{21}^{B} p+\tilde{a}_{22}^{B}\right)=1 .
\end{aligned}
$$

Equations [A1] and [A2] refer to commodities 1 and 2 if produced in country A, and similarly equations [B1] and [B2] refer to the possible production of commodities in country B. Each of these four equations establishes a relationship between $p$ and $r$. The relationship is direct $-p$ rises as $r$ increases - in the case of equations [A1] and [B1], whereas it is inverse $-p$ falls as $r$ increases - in the case of equations [A2] and [B2]. There may be several positions of these curves. Following Gibson, consider the case depicted in Figure 1. 


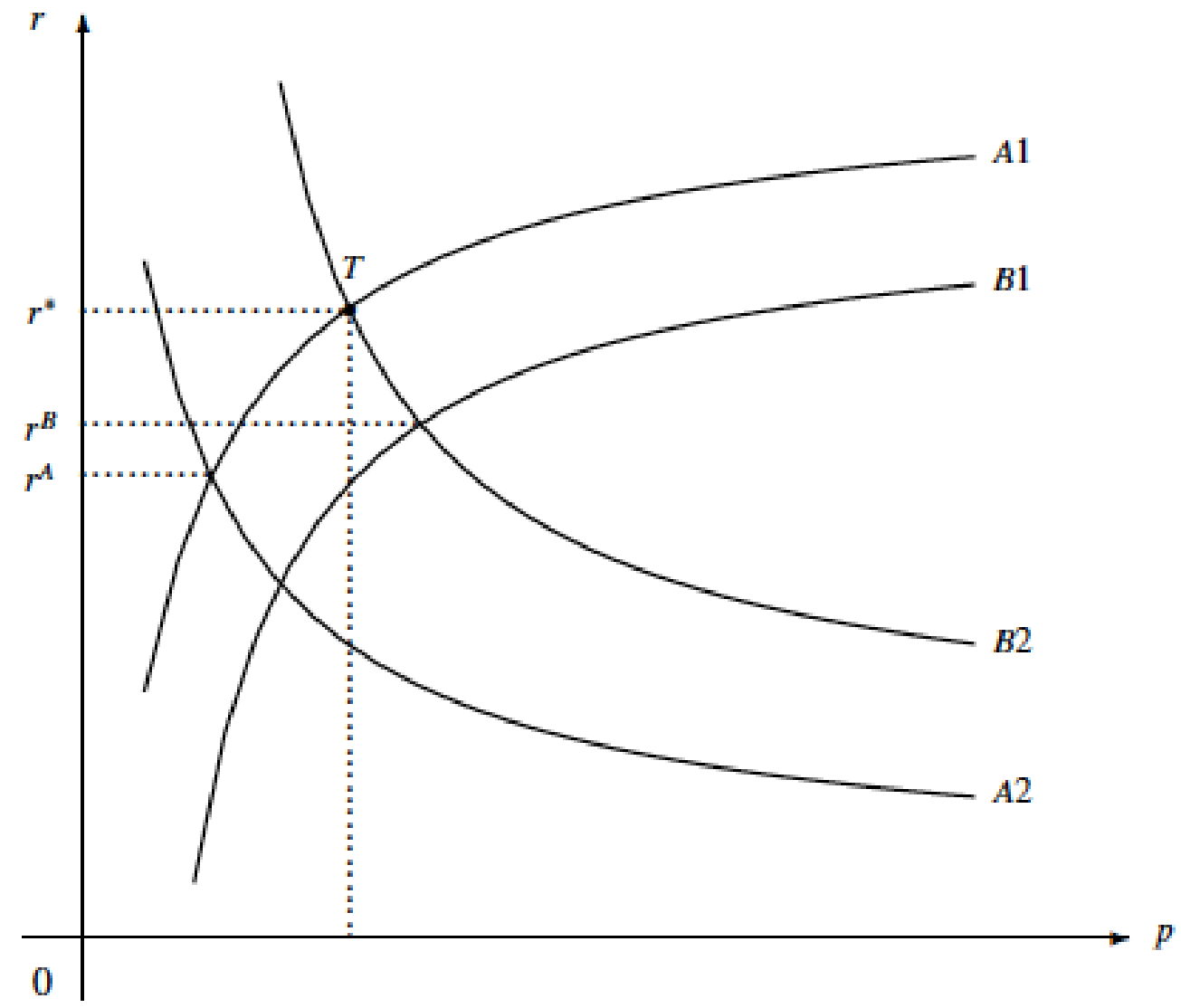

Figure 1 - Price equations.

Point $T$ in Figure 1 corresponds to a situation in which country A is specialized in the production of commodity 1 and country B in the production of commodity 2 . This international allocation of production allows capitalists, in both countries, to obtain a rate of profit $r^{*}$ that is higher than the autarchic ones, namely $r^{A}$ and $r^{B} .^{14}$

As for unequal exchange, Gibson maintains that, trading at a price $p^{*}$, country $\mathrm{B}$ is paying foreign commodities more than it would have done if its real wage rate had been at the same level as in country A. This is proved plotting in the same figure the curve B2', built with the technical coefficients of commodity 2 in country B and the real wage rate of country A.

\footnotetext{
${ }^{14}$ There is a logical analogy between the choice among the possible alternative specializations in a twocountry system and the choice of technique in a closed economy with two different qualities of labour, that are accordingly remunerated at different wage rates.
} 


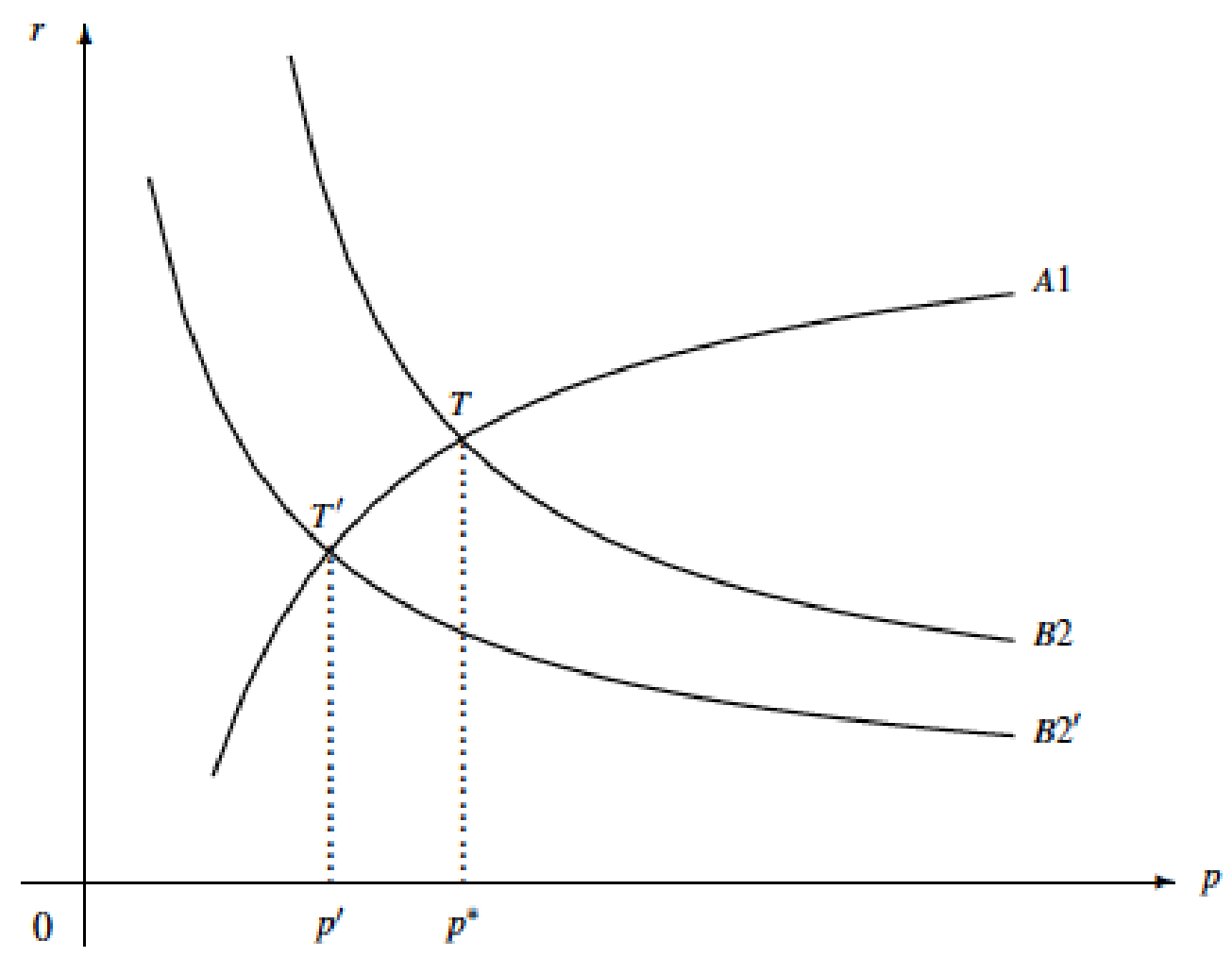

Figure 2 - Unequal exchange.

In Figure 2, the intersection of the curves A1 and B2' determines the price of commodity 1 in terms of commodity $2 p^{\prime}$ in the event the real wage rate in country $\mathrm{B}$ being the same as in country A. Since $p^{\prime}<p^{*}$, Gibson concludes that country B pays a greater quantity of commodity 2 for each unit of commodity 1 imported from A due to its lower real wage rate. In particular, he claims that the difference $p^{*}-p$ ' measures the flow of surplus value toward the centre, in terms of commodity 2 , per unit of commodity 1 imported by the periphery.

\subsection{Specialization reversal and absolute advantage}

According to Gibson, if a tendency of the wage rate in country B toward the level of country A is at work, then that could bring about a reversal of the pattern of trade specialization. This case is illustrated by means of Figure 3. The argument starts from point $T$, which is the solution to the problem of international allocation of production for the initial levels of the real wage rate in the two countries. Then, an increase in the real wage rate in the periphery, namely country B, is assumed to take place and, accordingly, the sociotechnical coefficients of production in country B changes. As a result, the curves based on price equations of country B become B1' and B2' instead of B1 and B2. 


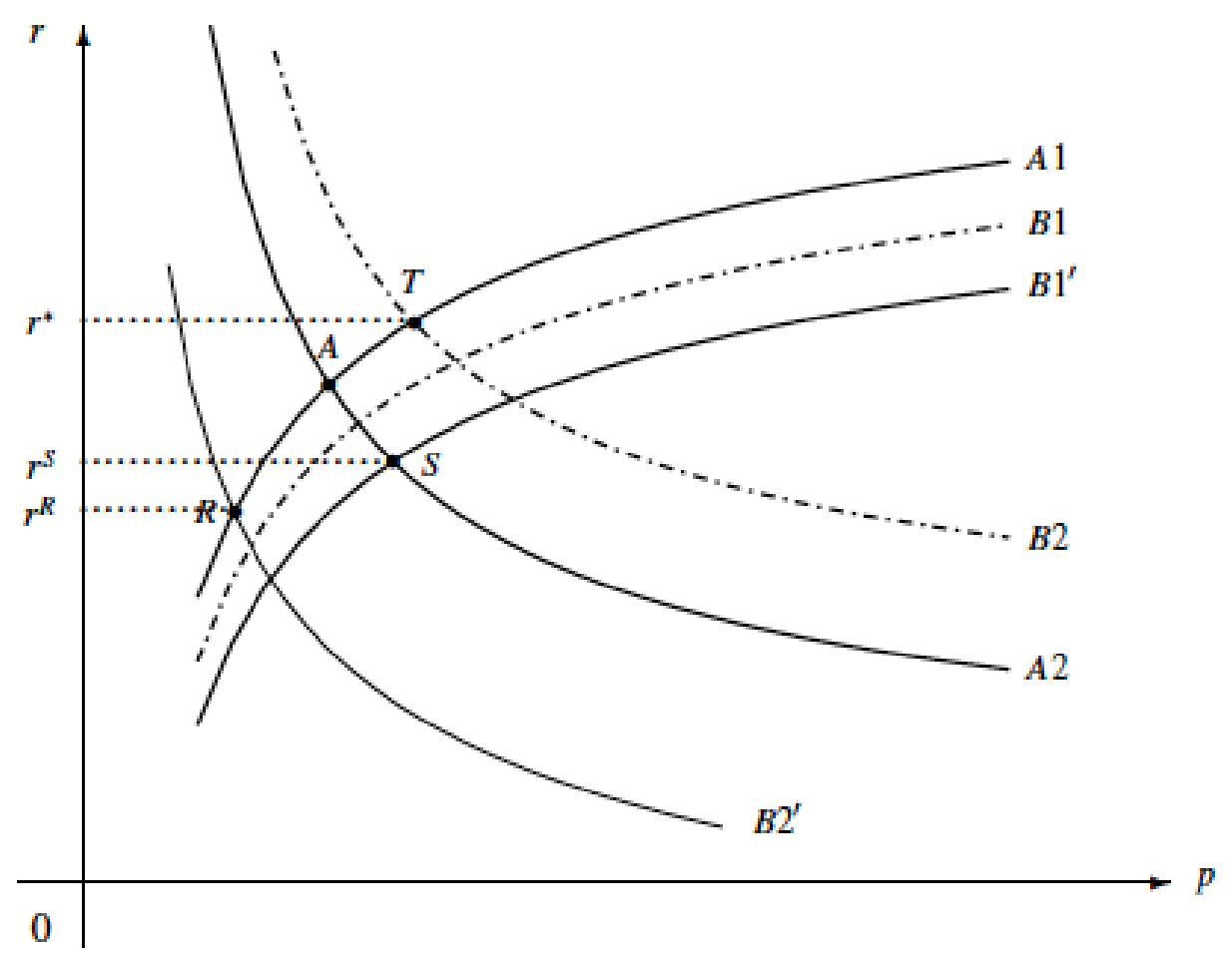

Figure 3 - Specialization reversal.

If country B was still specialized in the production of commodity 2, then the rate of profit would fall from $r^{*}$ to $r^{R}$. However, Gibson notes that a change in the pattern of specialization is more profitable in the new situation. In fact, producing commodity 1 in country B and commodity 2 in country A allows capitalists to obtain a rate of profit $r^{S}>$ $r^{R}$.

Gibson's conclusion is that an increase in the real wage rate in the peripheral country leads to a fall in the price $p$ of commodity 1 in terms of commodity 2, unless a reversal of the pattern of specialization takes place. In the latter event, the price $p$ may even increase.

What Gibson does not seem to be aware is that, in Figure 3, in point $\mathrm{A}$-i.e. the interception between curves A1 and A2 - capitalists would obtain a rate of profit even greater than $r^{S}$. This means that if capitalists are free to invest where they earn the highest rate of profits, they will invest in country A only, concentrating all productions in that country.

In other words, in the case represented in Figure 3, country A has an absolute advantage in both sectors. Under the assumption of free capital mobility, that entails that both the commodities will be produced in country A. This possibility was explicitly investigated by Brewer (1985), and later by Parrinello (2010). The rest of the paper will be focused on it. 


\section{Absolute advantages in Brewer}

The first paper that shows explicitly how absolute advantages may determine the allocation of production among countries is Brewer's (1985). The article contains a very simplified model, with two countries and two commodities produced by labour only. These simplifications allow us to understand how the interplay of comparative and absolute advantages affects the international location of production, according to the various regimes concerning capital and the degree of wage flexibility. One of the main conclusions drawn from the model will be that 'the assumptions of fixed wages and mobile capital ensure that the location of production is determined by absolute and not by comparative advantage' (Brewer, 1985, p. 177).

Let us see the details of the model. As in the previous section, let us consider an economic system with two countries $(A$ and $B)$ where two commodities ( 1 and 2$)$ are produced by unassisted labour only - clearly this implies that both commodities are pure consumption goods. Let $\ell_{i}^{X}$ denote, as above, the quantity of labour necessary to produce 1 unit of commodity $i$ in country $X$, with $i=1,2$ and $X=A, B$. Suppose that the $\ell_{i}^{X}$ s are independent of the level of production. If there is free trade among countries and there are no transaction costs, the same prices, $p_{1}$ and $p_{2}$, (expressed in terms of a suitable numeraire) will prevail in both countries. The quantities of labour available in the two countries - denoted by $L^{A}$ and $L^{B}$ - are given. This means that workers cannot freely move across countries. Hence, real wages may diverge between countries. In order to make comparisons easier we assume, following Brewer, that physical wages in the two countries are different quantities of the same composite commodity, whose unit is defined by vector $\mathbf{b}=\left[b_{1}, b_{2}\right]$. Accordingly, the physical wage rate $w^{X}$ corresponds to the number of baskets $\mathbf{b}$ that a worker can purchase in country $X$ with one unit of labour. In what follows, it is convenient to adopt basket $\mathbf{b}$ as numeraire of the price system, that is, to impose

$$
p_{1} b_{1}+p_{2} b_{2}=1 \text {. }
$$

In this way, $w^{X}$ indicates the wage rate in both physical and value terms in country $X$; henceforth we will speak of wages simply, without any need for further specification.

Since Brewer assumes that commodities are produced by means of unassisted labour, capital is constituted by wages advanced by capitalists to workers at the beginning of the production period. Capital stocks owned by the capitalists of each country - expressed in terms of the numeraire commodity - are denoted by $K^{A}$ and $K^{B} .{ }^{15}$ Brewer seems to consider these capital stocks as given magnitudes, in the same way as the endowments of factors of production in neoclassical models. Among the cases studied by Brewer, there is also the possibility that capital, differently from labour, can move freely between countries.

Thanks to the simplifying assumption that commodities are produced by means of labour only, it is easy for Brewer to define comparative and absolute advantages. Country $A$ is said to have a comparative advantage in producing (say) commodity 1 if

\footnotetext{
15 There is a certain ambiguity about the stocks of capital $K^{A}$ and $K^{B}$. Since capital consists of wages paid ex ante and wages consist physically of the numeraire commodity, then $K^{A}$ and $K^{B}$ are, at the same time, amounts of value and quantities of the composite commodity in which these amounts are spent.
} 


$$
\frac{\ell_{1}^{A}}{\ell_{2}^{A}}<\frac{\ell_{1}^{B}}{\ell_{2}^{B}} .
$$

Moreover, country $A$ is said to have an absolute advantage in producing (say) commodity 1 if $^{16}$

$$
w^{A} \ell_{1}^{A}<w^{B} \ell_{1}^{B}
$$

(in both definitions the case with weak inequalities is ignored). Without loss of generality, countries and commodities can always be numbered so that country $A$ has a comparative and (in the case of exogenous wages) an absolute advantage in commodity 1 . In fact, leaving aside the borderline case where (2) and (3) are equalities, there is always a country having an absolute advantage in at least one commodity; call $A$ this country; moreover, each country always has a comparative advantage in one commodity (equalities apart); call commodity 1 the commodity where country $A$ has a comparative advantage.

In this framework Brewer considers four alternative regimes, according to the flexibility/rigidity of wages and the mobility/immobility of capital.

Case 1. (Fixed wages; capital immobile). Here we are in a situation similar to that considered in section 2 referring to Ricardo's theory. The rates of profit

$$
\begin{aligned}
& r_{1}^{A}=\frac{p_{1}-w^{A} \ell_{1}^{A}}{w^{A} \ell_{1}^{A}}, r_{2}^{A}=\frac{p_{2}-w^{A} \ell_{2}^{A}}{w^{A} \ell_{2}^{A}} \\
& r_{1}^{B}=\frac{p_{1}-w^{B} \ell_{1}^{B}}{w^{B} \ell_{1}^{B}}, r_{2}^{B}=\frac{p_{2}-w^{B} \ell_{2}^{B}}{w^{B} \ell_{2}^{B}}
\end{aligned}
$$

do not need to equalize between countries because capital is immobile.

Without international trade the rates of profit will tend to be equalized within each country:

$$
r_{1}^{A}=r_{2}^{A}=r^{A}, \text { that is, } \frac{p_{1}^{A}}{p_{2}^{A}}=\frac{\ell_{1}^{A}}{\ell_{2}^{A}}
$$

and

$$
r_{1}^{B}=r_{2}^{B}=r^{B}, \text { that is, } \frac{p_{1}^{B}}{p_{2}^{B}}=\frac{\ell_{1}^{B}}{\ell_{2}^{B}}
$$

where $r^{A}$ and $r^{B}$ are the national general rates of profit. In this autarchic equilibrium, price vectors are $\mathbf{p}^{A}$ and $\mathbf{p}^{B}$, in the respective country (see Figure 4 below).

If international trade is allowed for (prices in this case will be the same between countries, that is, $p_{1}$ and $p_{2}$ ), the rates of profit may diverge between industries within each country, thus making it convenient for each country to specialize in the production of the commodity with the highest rate of profit. Observe that, as prices satisfy condition (1), they must lie on the segment $S$ of Figure 4.

\footnotetext{
${ }^{16}$ Differently from the notion of comparative advantages, in the definition of absolute advantages enter both technological and institutional elements. Absolute advantages are defined a priori only when wages are exogenously given.
} 


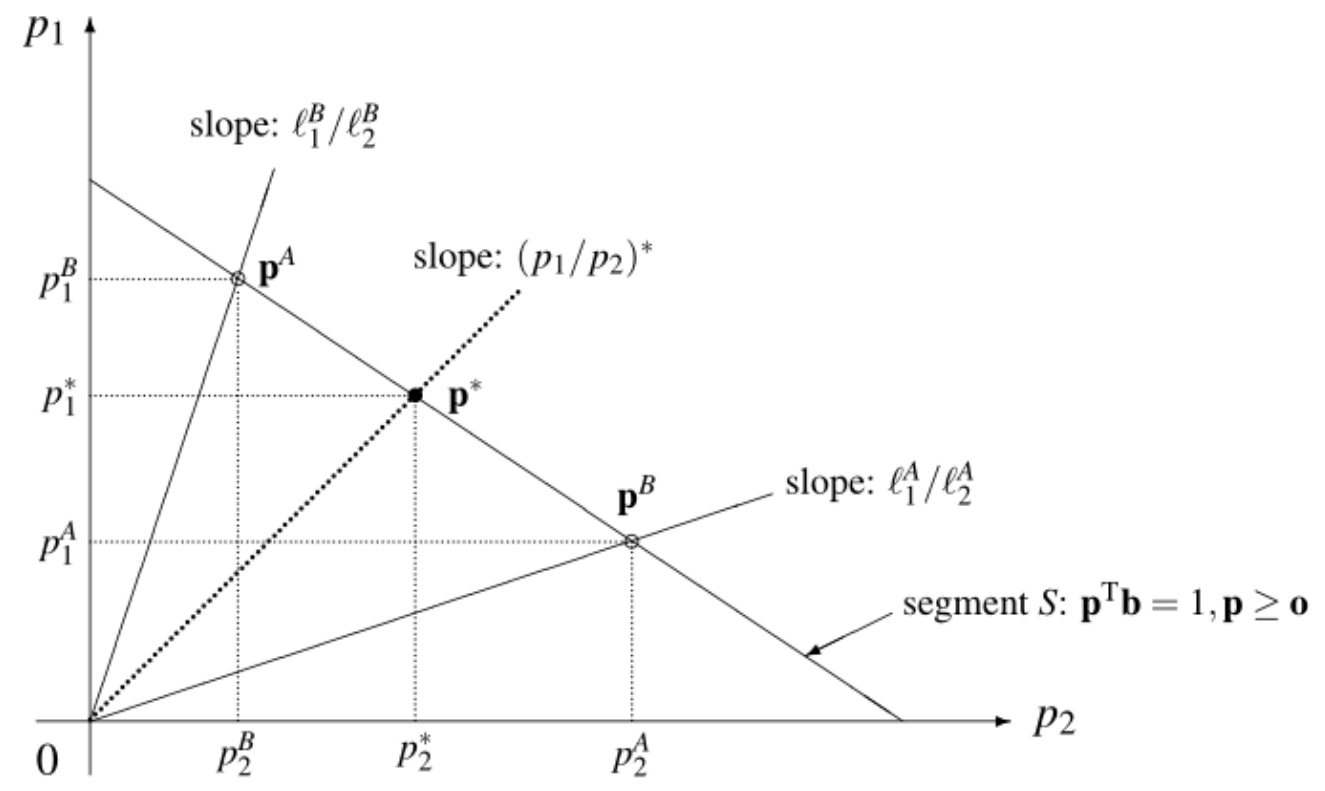

Figure 4 - Opening to international trade.

If the countries open to international trade, and if a relative price prevails in the following interval, which is not empty thanks to the assumptions on comparative advantages (2),

$$
\frac{\ell_{1}^{A}}{\ell_{2}^{A}}<\left(\frac{p_{1}}{p_{2}}\right)^{*}<\frac{\ell_{1}^{B}}{\ell_{2}^{B}}
$$

we have

$$
\begin{array}{lll}
p_{1}^{*}>p_{1}^{A}, & \text { hence } & r_{1}^{A^{*}}>r^{A} \\
p_{1}^{*}<p_{1}^{B}, \text { hence } & r_{1}^{B^{*}}<r^{B} \\
p_{2}^{*}<p_{2}^{A}, \text { hence } & r_{2}^{A^{*}}<r^{A} \\
p_{2}^{*}>p_{2}^{B}, \text { hence } r_{2}^{B^{*}}>r^{B} .
\end{array}
$$

The prevalence of a relative price within the interval ${ }^{17}$ defined in (5) makes it convenient to both countries to specialize in one production: given the regime concerning comparative advantages, country $A$ produces commodity 1 and country $B$ produces commodity 2 . As correctly anticipated by Ricardo, the location of production is determined, in this case, by comparative advantages. Observe that inequality (5) is logically equivalent to that obtained at the end of Section 2.

Case 2. (Fixed wages; capital mobile). Two sub-cases are possible.

Sub-case 2.1 - Each country has an absolute advantage in producing one commodity, that is,

\footnotetext{
${ }^{17}$ The issue of indeterminacy of the international terms of trade has been largely debated: see, for example, Parrinello (1988) and Vasudevan (2012).
} 


$$
\begin{aligned}
& w^{A} \ell_{1}^{A}<w^{B} \ell_{1}^{B} \\
& w^{A} \ell_{2}^{A}>w^{B} \ell_{2}^{B}
\end{aligned}
$$

For each value of $p_{1}$ and $p_{2}$, inequalities (6) can be rewritten as

$$
\begin{aligned}
& \frac{p_{1}}{w^{A} \ell_{1}^{A}}-1>\frac{p_{1}}{w^{B} \ell_{1}^{B}}-1 \\
& \frac{p_{2}}{w^{A} \ell_{2}^{A}}-1<\frac{p_{2}}{w^{B} \ell_{2}^{B}}-1
\end{aligned}
$$

that is,

$$
\begin{aligned}
& r_{1}^{A}>r_{1}^{B} \\
& r_{2}^{A}<r_{2}^{B}
\end{aligned}
$$

The advantage of each nation in one production only avoids that each country is overcome by the competition of the other one. Each country will specialize in one production, the one where it may yield the highest rate of profit, and will import the other commodity; given the regime of comparative advantages, country $A$ produces commodity 1 and imports commodity 2 ; vice versa for country $B$. This case corresponds to that considered by Gibson in Figure 1 above (point $T$ ). Capital mobility will lead the profit rates of the processes in use to converge to a uniform level:

$$
r_{1}^{A}=r_{2}^{B}, \text { that is, } \frac{p_{1}}{w^{A} \ell_{1}^{A}}-1=\frac{p_{2}}{w^{B} \ell_{2}^{B}}-1 .
$$

From (7) we deduce the relative price that makes the rates of profit uniform between countries:

$$
\frac{p_{1}}{p_{2}}=\frac{w^{A} \ell_{1}^{A}}{w^{B} \ell_{2}^{B}}
$$

In this sub-case, the location of production is still determined by comparative advantages. Sub-case $\mathbf{2 . 2}$ - One country has an absolute advantage in producing both commodities, that is,

$$
\begin{aligned}
& w^{A} \ell_{1}^{A}<w^{B} \ell_{1}^{B} \\
& w^{A} \ell_{2}^{A}<w^{B} \ell_{2}^{B}
\end{aligned}
$$

For each value of $p_{1}$ and $p_{2}$, inequalities (8) can be rewritten as

$$
\begin{aligned}
& \frac{p_{1}}{w^{A} \ell_{1}^{A}}-1>\frac{p_{1}}{w^{B} \ell_{1}^{B}}-1 \\
& \frac{p_{2}}{w^{A} \ell_{2}^{A}}-1>\frac{p_{2}}{w^{B} \ell_{2}^{B}}-1
\end{aligned}
$$

that is,

$$
\begin{aligned}
& r_{1}^{A}>r_{1}^{B} \\
& r_{2}^{A}>r_{2}^{B}
\end{aligned}
$$

For any prices system, the equalization of the profit rates cannot take place between countries: inequalities $\left(8^{\prime}\right)$ or $\left(8^{\prime \prime}\right)$ hold for any $p_{1}$ and $p_{2}$. Country $B$ is overall less competitive 
than $A$. Capital funds available in country $B$ will flow towards the industries of country $A$, as they guarantee a rate of profit higher than that that can be yielded in country $B$. In principle, this capital outflow will continue till the complete 'desertification' of the industrial system of country $B$ : production will be concentrated totally in country $A$.

The equalization of the rates of profit will take place within country $A$ :

$$
r_{1}^{A}=r_{2}^{A} \text {, that is, } \frac{p_{1}}{w^{A} \ell_{1}^{A}}-1=\frac{p_{2}}{w^{A} \ell_{2}^{A}}-1 \text {. }
$$

From (9) we deduce the relative price that makes the rates of profit uniform in country $A$ :

$$
\frac{p_{1}}{p_{2}}=\frac{\ell_{1}}{\ell_{2}} .
$$

In this sub-case, the location of production is determined by absolute advantages. Observe that this is the case already present in Gibson's Figure 3 above (point $A$ ) but, apparently, he did not notice this possibility.

Case 3. (Flexible wages; capital mobile). Capital mobility equalizes the rate of profit on the production process operated. Wage flexibility - according to Brewer - eliminates possible absolute advantages in producing both commodities. ${ }^{18}$ The equalization of the rates of profit will take place between countries and each country will specialize in one production. The location of production is still determined by comparative advantages.

Case 4. (Flexible wages; capital immobile). As in case 3, wage flexibility eliminates possible absolute advantages in both productions. There remain only comparative advantages that will lead each country to specialize in one production. The rates of profit on the production processes operated will not equalize, as there is no capital mobility. Like in the case considered by Ricardo (here, case 1) the location of production is still determined by comparative advantages.

\section{Production with one capital good}

The sharpness of Brewer's results is evidently due to the simplifying assumption that commodities are produced by unassisted labour only. Parrinello (2010) took a first step to overcome this limitation: he investigated the trade and the investment relations of two countries within a simple Hicks-Spaventa model with two commodities produced by labour and one capital good. In this section we recall briefly the structure of Parrinello's framework. In Section 7 we shall provide a generalization of Parrinello's framework to any number of commodities.

\footnotetext{
${ }^{18}$ In fact, in the model considered by Brewer, if wages are flexible, should a country have absolute advantages in producing both commodities, capital will flow towards that country attracted by the higher rates of profit; the ensuing increase in production in that country will raise wages until the point where the absolute advantages in both productions disappear.
} 
As in the previous sections, there are two countries, $A$ and $B$, and two commodities, 1 and 2 . In each country there exists only one method of production for each commodity, which may differ by country. The generic method of production of commodity $i$ in country $X$ can be described as follows,

$$
a_{i 1}^{X} \oplus \ell_{i}^{X} \rightarrow 1 \text { unit of commodity } i \text { in country } X ; i=1,2 ; X=A, B,
$$

where $a_{i 1}^{X}$ and $\ell_{i}^{X}$ are the quantity of commodity 1 and of labour employed to produce 1 unit of commodity $i$ in country $X$. Coefficients $a_{i 1}^{X}$ and $\ell_{i}^{X}$ do not depend on output levels. We can thus define four alternative techniques:

$$
\mathbf{A}=\left[\begin{array}{ll}
a_{11}^{A} & \ell_{1}^{A} \\
a_{21}^{A} & \ell_{2}^{A}
\end{array}\right] ; \quad \mathbf{B}=\left[\begin{array}{ll}
a_{11}^{B} & \ell_{1}^{B} \\
a_{21}^{B} & \ell_{2}^{B}
\end{array}\right] ; \mathbf{M}^{A, B}=\left[\begin{array}{ll}
a_{11}^{A} & \ell_{1}^{A} \\
a_{21}^{B} & \ell_{2}^{B}
\end{array}\right] \text { and } \mathbf{M}^{B, A}=\left[\begin{array}{ll}
a_{11}^{B} & \ell_{1}^{B} \\
a_{21}^{A} & \ell_{2}^{A}
\end{array}\right] .
$$

In a non-globalized system each country has access to one technique only: country $A$ produces both commodities by technique $\mathbf{A}$ and country $B$ produces both commodities by technique $\mathbf{B} .{ }^{19}$ In a globalized system each country can also access 'mixed' techniques $\mathbf{M}^{A, B}$ and $\mathbf{M}^{B, A}$. Clearly, both the non-mixed techniques $\mathbf{A}$ and $\mathbf{B}$ are still available; the choice is thus among four techniques: $\mathbf{M}^{A, B}, \mathbf{M}^{B, A}, \mathbf{A}$ and $\mathbf{B}$. The technique actually adopted in the globalized economy will depend on income distribution. The choice of technique in the globalized economy can be addressed by the comparison of the wage- profit curves. In our case, we have to deal with three variables, the rate of profit $r$ - which in the globalized economy is uniform among countries - and two wage rates, each ruling in the respective country: $w^{A}$ and $w^{B}$.

For a mixed technique, the wage-profit curve is

$$
r=M\left(w^{X}, w^{Y}\right) \equiv \frac{1}{a_{11}^{X}+a_{21}^{Y} \ell_{1}^{X} w^{X}\left(1-\ell_{2}^{Y} w^{Y}\right)^{-1}}-1 \text {, with } X, Y=A, B \text { and } X \neq Y .
$$

For a non-mixed technique, the wage-profit curve is

$$
\begin{aligned}
& r=N\left(w^{X}\right) \\
& \equiv \frac{1}{a_{11}^{X}+a_{21}^{X} \ell_{1}^{X} w^{X}\left(1-\ell_{2}^{X} w^{X}\right)^{-1}} \\
& -1, \text { with } X=A, B .
\end{aligned}
$$

For our purposes, which is that of ascertaining that it is possible that a non-mixed technique dominates the other three, at least under some distributive configuration, it is convenient to consider - like Parrinello does - the wage rate of one country as fixed (at a parametric level). Assume, for example, that $w^{B}$ is fixed. We then plot on the same diagram the wage-profit curves ensuing from (10) and (11). From (11) we get immediately that if the wage rate in country $B$ is taken as given, $w^{B}=\bar{w}^{B}$, then the corresponding rate of profit will be given as well, at the level $r^{B}=N\left(\bar{w}^{B}\right)$. The other relations, $r=$ $M\left(w^{A}, \bar{w}^{B}\right), r=M\left(\bar{w}^{B}, w^{A}\right)$ and $r=N\left(w^{A}\right)$, are three decreasing equilateral hyperbola.

\footnotetext{
${ }^{19}$ In actual fact, as stressed by Parrinello (2002), even if the two countries had the same technological knowledge, they can very well have different techniques because of 'institutional factors' that can affect the conditions of production.
} 
One possible scenario is that depicted in Figure 5 below, where the wage rate in coun$\operatorname{try} A$ is represented on the horizontal axis and the (uniform) rate of profit is represented on the vertical axis.

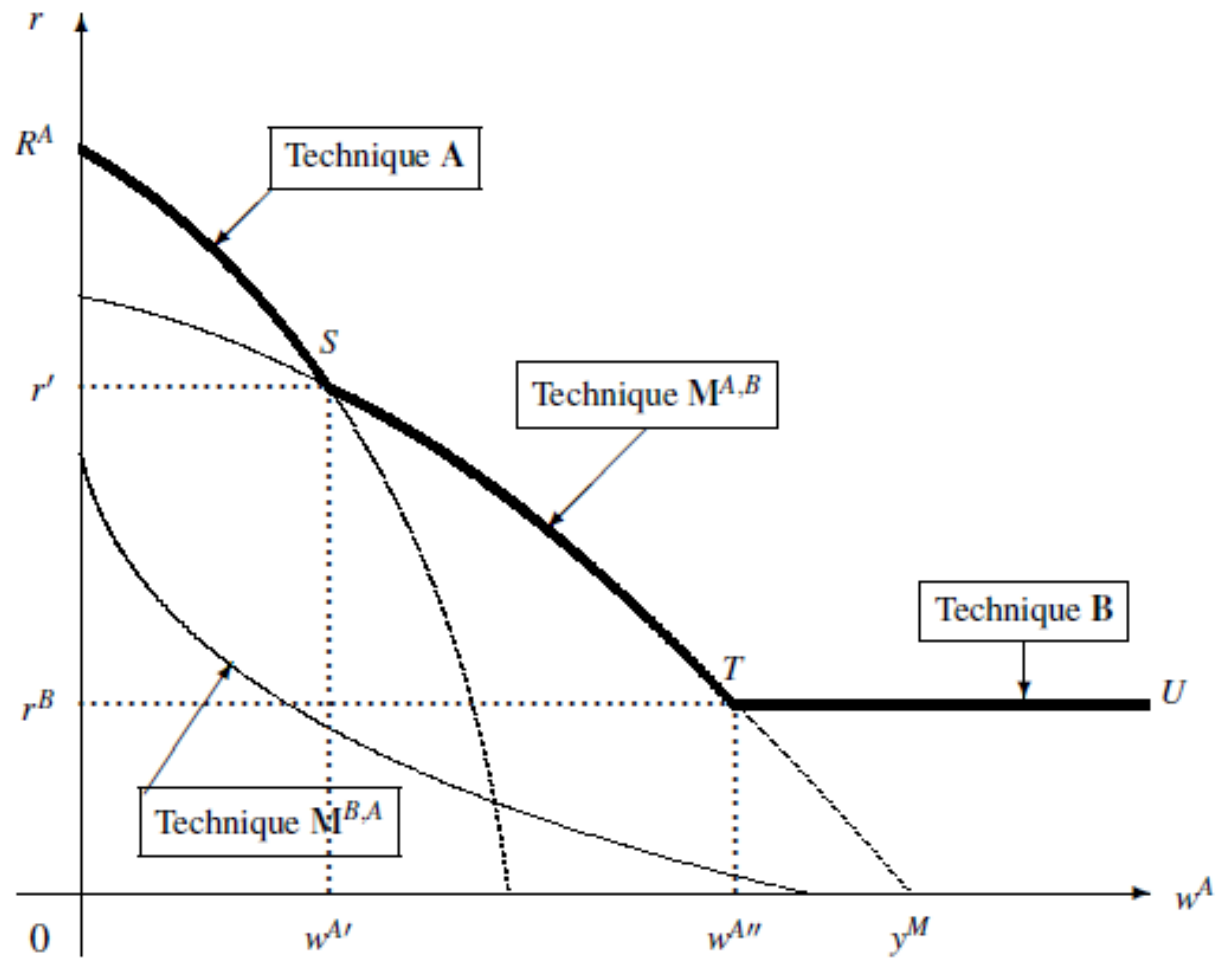

Figure 5 - Wage-profit frontier, 1 capital good, case I.

In this case, technique $\mathbf{M}^{B, A}$ is dominated by at least one technique. If the wage rate in country $A$ is fixed in the interval $\left(w^{A \prime}, w^{A \prime}\right)$ the more profitable technique is a 'mixed' technique, that is, a technique where one commodity (commodity 1 ) is produced in country $A$ and the other commodity (commodity 2 ) is produced in country $B$. Each country specializes in this case in one production. Should the wage rate in country $A$ be fixed in intervals $\left[0, w^{A \prime}\right)$ or $\left(w^{A^{\prime \prime}}, y^{M}\right)$, capitalists will find it convenient to invest their entire capitals in country $A$ or in country $B$, respectively. In each of these cases, production will be entirely attracted to one country only, leaving the other country a 'desert'.

Clearly, the curves drawn in Figure 5 represent just one possible case. There may be cases where only mixed technologies appear on the technological frontier: in this case each country specializes in one production only and imports the other good from the other country. But what we learn from this analysis is that the case where capitalists find it convenient to concentrate all production in one country cannot be excluded. We cannot even rule out the case where one country dominates both the other country and any 'mixed' technique: Figure 6 shows the case where country $B$ dominates country $A$ at any level of the wage rate in country $A$. 


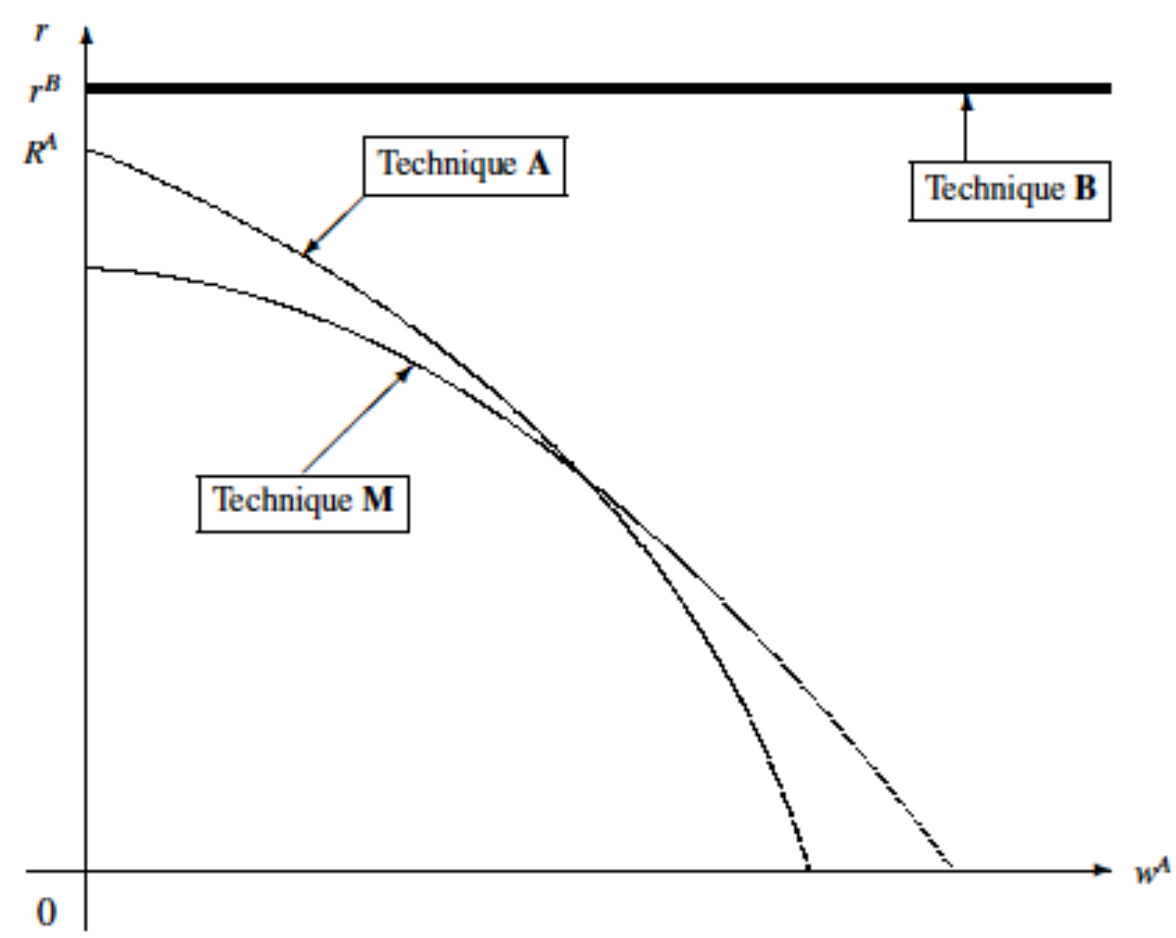

Figure 6 - Wage-profit frontier, 1 capital good, case II.

These conclusions generalize the results obtained by Brewer to the case of production with labour and one capital good. In the following section we propose a further generalization to the case with a generic number of commodities.

\section{Production with more capital goods}

We consider a model with two countries, $A$ and $B$, that can produce the same set of $K$ commodities. ${ }^{20}$ In each country, one and only one method of production is known for each commodity. The method of production of a commodity can be described by a set of technical coefficients, which are assumed independent of output levels. The generic method of production of commodity $k$ in country $A$ is

$$
a_{k, 1} \oplus a_{k, 2} \oplus \ldots \oplus a_{k, K} \oplus \alpha_{k} \rightarrow 1 \text { unit of commodity } k,
$$

where $a_{k i}$ is the quantity of commodity $i$ employed to produce 1 unit of commodity $k$, and $\alpha_{k}$ is the quantity of labour employed to produce 1 unit of commodity $k$, with $k, i=$ $1,2, \ldots, K$. Analogously, the generic method of production of commodity $k$ in country $B$ is

${ }^{20}$ This assumption is quite restrictive. It is adopted here as our focus is to depict the possibility that the production of all commodities tends to concentrate in one country only as the effect of capital mobility. Clearly, if one or more commodities were produced in one country only, the tendency to industrial 'desertification' could never be undergone by that country. 


$$
b_{k, 1} \oplus b_{k, 2} \oplus \ldots \oplus b_{k, K} \oplus \beta_{k} \rightarrow 1 \text { unit of commodity } k,
$$

where $b_{k i}$ is the quantity of commodity $i$ employed to produce 1 unit of commodity $k$, and $\beta_{k}$ is the quantity of labour employed to produce 1 unit of commodity $k$, with $k, i=1,2$, $\ldots, K$.

We have thus two alternative methods for each commodity, one in country $A$ and the other in country $B$. The ensuing techniques ${ }^{21}$ of the 'globalized' economy are thus $2^{K}$ techniques: besides the 'national' techniques,

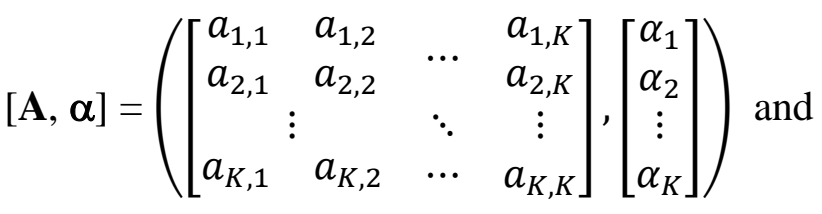

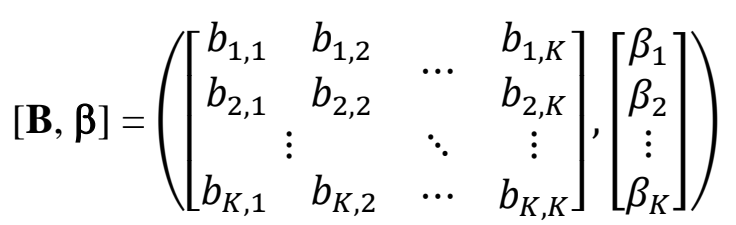

we have $2^{K}-2$ 'mixed' techniques, where a subset of $K_{A}$ commodities is produced in $A$ and the remaining $K_{B}=K-K_{A}$ commodities are produced in $B$.

As is known, each 'national' technique can be associated with a decreasing relation between the rate of profit and the wage rate (expressed in terms of any bundle of commodities).

Deriving a similar relation in the case of a mixed technique is more complicated. To this purpose, we can represent the technical matrix of the generic mixed technique as follows, where the first $H$ commodities (with $H>0$ ) are produced in country $A$ and the last $F$ (with $F>0$ ) in country $B$, with $H+F=K$.

$$
\begin{aligned}
& \left.\left.\left(\left[\begin{array}{cccccccc}
a_{1,1} & a_{1,2} & \cdots & a_{1, H} & a_{1, H+1} & a_{1, H+2} & \cdots & a_{1, H+F} \\
a_{2,1} & a_{2,2} & \cdots & a_{2, H} & a_{2, H+1} & a_{2, H+2} & \cdots & a_{2, H+F} \\
\vdots & \vdots & \ddots & \vdots & \vdots & \vdots & \ddots & \vdots \\
a_{H, 1} & a_{H, 2} & \cdots & a_{H, H} & a_{H, H+1} & a_{H, H+2} & \cdots & a_{H, H+F} \\
b_{H+1,1} & b_{H+1,2} & \cdots & b_{H+1, H} & b_{H+1, H+1} & b_{H+1, H+2} & \cdots & b_{H+1, H+F} \\
b_{H+2,1} & b_{H+2,2} & \cdots & b_{H+2, H} & b_{H+2, H+1} & b_{H+2, H+2} & \cdots & b_{H+2, H+F} \\
\vdots & \vdots & \ddots & \vdots & \vdots & \vdots & \ddots & \vdots \\
b_{H+F, 1} & b_{H+F, 2} & \cdots & b_{H+F, H} & b_{H+F, H+1} & b_{H+F, H+2} & \cdots & b_{H+F, H+F}
\end{array}\right], \begin{array}{c}
\alpha_{1} \\
\alpha_{2} \\
\vdots \\
\alpha_{H}
\end{array}\right]\right)\left[\begin{array}{c}
\beta_{H+1} \\
\beta_{H+2} \\
\vdots \\
\beta_{H+F}
\end{array}\right]\right) \\
& = \\
& =\left(\begin{array}{lll}
\mathbf{A}^{A} & \mathbf{A}^{B} & \boldsymbol{\alpha}^{A} \\
\mathbf{B}^{A} & \mathbf{B}^{B} & \boldsymbol{\beta}^{B}
\end{array}\right) .
\end{aligned}
$$

The first $H$ rows of this matrix represent the processes operated in country $A$ employing: commodities produced in country $A$ (whose coefficients are included in matrix $\mathbf{A}^{A}$ ), commodities produced in commodity $B$ (whose coefficients are included in matrix $\mathbf{A}^{B}$ ) and

\footnotetext{
${ }^{21}$ As usual, a 'technique' is a set of methods of production where each commodity is produced by one method.
} 
labour (whose coefficients are included in vector $\boldsymbol{\alpha}^{A}$ ); the last $F$ rows represent the processes operated in country $B$ employing: commodities produced in country $A$ (whose coefficients are included in matrix $\mathbf{B}^{A}$ ), commodities produced in commodity $B$ (whose coefficients are included in matrix $\mathbf{B}^{B}$ ) and labour (whose coefficients are included in vector $\left.\beta^{B}\right)$.

Wages are considered in physical terms. Let $\mathbf{a}$ and $\mathbf{b}$ be two $(K, 1)$ vectors indicating the unit wage-bundle of workers in country $A$ and in country $B$, respectively. Vectors a and $\mathbf{b}$ need not be equal and each of them can include, in general, both commodities produced in country $A$, sub-vectors $\mathbf{a}^{A}$ and $\mathbf{b}^{A}$, and those produced in country B, subvectors $\mathbf{a}^{B}$ and $\mathbf{b}^{B}$. That is:

$$
\mathbf{a}=\left[\begin{array}{l}
\mathbf{a}^{A} \\
\mathbf{a}^{B}
\end{array}\right] \text { and } \mathbf{b}=\left[\begin{array}{l}
\mathbf{b}^{A} \\
\mathbf{b}^{B}
\end{array}\right]
$$

Wage levels, $w^{A}$ are the units of wage-bundles a paid in country $A$ for 1 unit of labour and $w^{B}$ are the units of wage-bundles $\mathbf{b}$ paid in country $B$ for 1 unit of labour. Therefore $w^{A}$. $\mathbf{a}$ and $w^{B} \cdot \mathbf{b}$ are the physical wage rates in the two countries.

Let $\mathbf{p}^{A}$ be the $(H, 1)$ vector whose entries are the prices of the commodities produced in $A$, and similarly $\mathbf{p}^{B}$ is the $(F, 1)$ price vector of those produced in country $B$. The price vector of the $K$ commodities is:

$$
\mathbf{p}=\left[\begin{array}{l}
\mathbf{p}^{A} \\
\mathbf{p}^{B}
\end{array}\right]
$$

The ensuing price equations - with wages paid in advance, at the beginning of the period of production - are:

$$
\left[\begin{array}{l}
\mathbf{p}^{A} \\
\mathbf{p}^{B}
\end{array}\right]=(1+r)\left[\begin{array}{ll}
\mathbf{A}^{A} & \mathbf{A}^{B} \\
\mathbf{B}^{A} & \mathbf{B}^{B}
\end{array}\right]\left[\begin{array}{l}
\mathbf{p}^{A} \\
\mathbf{p}^{B}
\end{array}\right]+(1+r)\left[\begin{array}{l}
\boldsymbol{\alpha}^{A} \cdot w^{A} \mathbf{a}^{\mathrm{T}} \mathbf{p} \\
\boldsymbol{\beta}^{B} \cdot w^{B} \mathbf{b}^{\mathrm{T}} \mathbf{p}
\end{array}\right] .
$$

Let us suppose, like in Parrinello, that the real wage in country $B$ is given; in our formulation this can be obtained by setting

$$
w^{B}=\bar{w}^{B} .
$$

For our purposes, it is useful to re-express the price equations of commodities produced in country $B$ by means of the socio-technical matrix. Let $\widetilde{\mathbf{B}}^{A}=\mathbf{B}^{A}+\bar{w}^{B} \boldsymbol{\beta}^{B} \mathbf{b}^{A^{\mathrm{T}}}$ and $\widetilde{\mathbf{B}}^{B}=$ $\mathbf{B}^{B}+\bar{w}^{B} \boldsymbol{\beta}^{B} \mathbf{b}^{B^{\mathrm{T}}}$ be the socio-technical coefficients - as in section 4 ; then:

$$
\begin{gathered}
\mathbf{p}^{B}=(1+r)\left[\left(\mathbf{B}^{A} \mathbf{p}^{A}+\mathbf{B}^{B} \mathbf{p}^{B}\right)+\bar{w}^{B} \boldsymbol{\beta}^{B}\left(\mathbf{b}^{A^{T}} \mathbf{p}^{A}+\mathbf{b}^{B^{\mathrm{T}}} \mathbf{p}^{B}\right)\right]= \\
=(1+r)\left[\left(\mathbf{B}^{A}+\bar{w}^{B} \boldsymbol{\beta}^{B} \mathbf{b}^{A^{\mathrm{T}}}\right) \mathbf{p}^{A}+\left(\mathbf{B}^{B}+\bar{w}^{B} \boldsymbol{\beta}^{B} \mathbf{b}^{B^{\mathrm{T}}}\right) \mathbf{p}^{B}\right]= \\
=(1+r)\left[\widetilde{\mathbf{B}}^{A} \mathbf{p}^{A}+\widetilde{\mathbf{B}}^{B} \mathbf{p}^{B}\right] .
\end{gathered}
$$

The price system of the globalized economy can thus be rewritten as:

$$
\left[\begin{array}{l}
\mathbf{p}^{A} \\
\mathbf{p}^{B}
\end{array}\right]=(1+r)\left[\begin{array}{ll}
\mathbf{A}^{A} & \mathbf{A}^{B} \\
\widetilde{\mathbf{B}}^{A} & \widetilde{\mathbf{B}}^{B}
\end{array}\right]\left[\begin{array}{l}
\mathbf{p}^{A} \\
\mathbf{p}^{B}
\end{array}\right]+(1+r)\left[\begin{array}{c}
\boldsymbol{\alpha}^{A} \cdot w^{A} \mathbf{a}^{\mathrm{T}} \mathbf{p} \\
\mathbf{o}
\end{array}\right]
$$


Moreover, we express commodity prices, in both countries, in terms of labour commanded in country $A$, that is, we impose

$$
w^{A} \mathbf{a}^{\mathrm{T}} \mathbf{p}=1
$$

(this normalization expresses each price in terms of 1 unit of labour in country A).

The price equations $\left(12^{\prime}\right)$ become thus

$$
\left[\begin{array}{l}
\mathbf{p}^{A} \\
\mathbf{p}^{B}
\end{array}\right]=(1+r)\left[\begin{array}{ll}
\mathbf{A}^{A} & \mathbf{A}^{B} \\
\widetilde{\mathbf{B}}^{A} & \widetilde{\mathbf{B}}^{B}
\end{array}\right]\left[\begin{array}{l}
\mathbf{p}^{A} \\
\mathbf{p}^{B}
\end{array}\right]+(1+r)\left[\begin{array}{c}
\boldsymbol{\alpha}^{A} \\
\mathbf{o}
\end{array}\right]
$$

or,

$$
\mathbf{p}=(1+r)(\mathbf{M p}+\boldsymbol{\mu})
$$

where

$$
\mathbf{M}=\left[\begin{array}{cc}
\mathbf{A}^{A} & \mathbf{A}^{B} \\
\widetilde{\mathbf{B}}^{A} & \widetilde{\mathbf{B}}^{B}
\end{array}\right] \text { and } \boldsymbol{\mu}=\left[\begin{array}{c}
\boldsymbol{\alpha}^{A} \\
\mathbf{o}
\end{array}\right]
$$

By solving $\left(12^{\prime \prime}\right)$ with respect to $\mathbf{p}$ we obtain a price vector as a function of parameter $r$,

$$
\mathbf{p}(r) \equiv(1+r)[\mathbf{I}-(1+r) \mathbf{M}]^{-1} \boldsymbol{\mu} .
$$

Let $\lambda^{*}$ be the dominant eigenvalue of $\mathbf{M}$; by Perron-Frobenius theorems we know that, if $r<\left(1-\lambda^{*}\right) / \lambda^{*}$, then the inverse matrix involved in the above expression is a continuously non-decreasing function of $r$. Hence $\mathbf{p}(r)$ is a non-decreasing vector of $r$. By solving (13) with respect to $w^{A}$ we obtain the real wage rate of country $A$ as a function of the rate of profit:

$$
w^{A}(r) \equiv \frac{1}{\mathbf{a}^{\mathrm{T}} \mathbf{p}(r)} .
$$

Hence, as $\mathbf{a} \geq \mathbf{0}$, relation $w^{A}(r)$ is decreasing with respect to $r$.

Each technique is thus associated to a continuously decreasing relation between the wage rate in country $A$ and the (uniform) rate of profit. Conclusions exactly analogous to those obtained in the previous sections can now be drawn; the only difference is that the wage-profit curves are now constituted by generic polynomial curves instead of equilateral hyperbola: see Figures 7 and 8. 


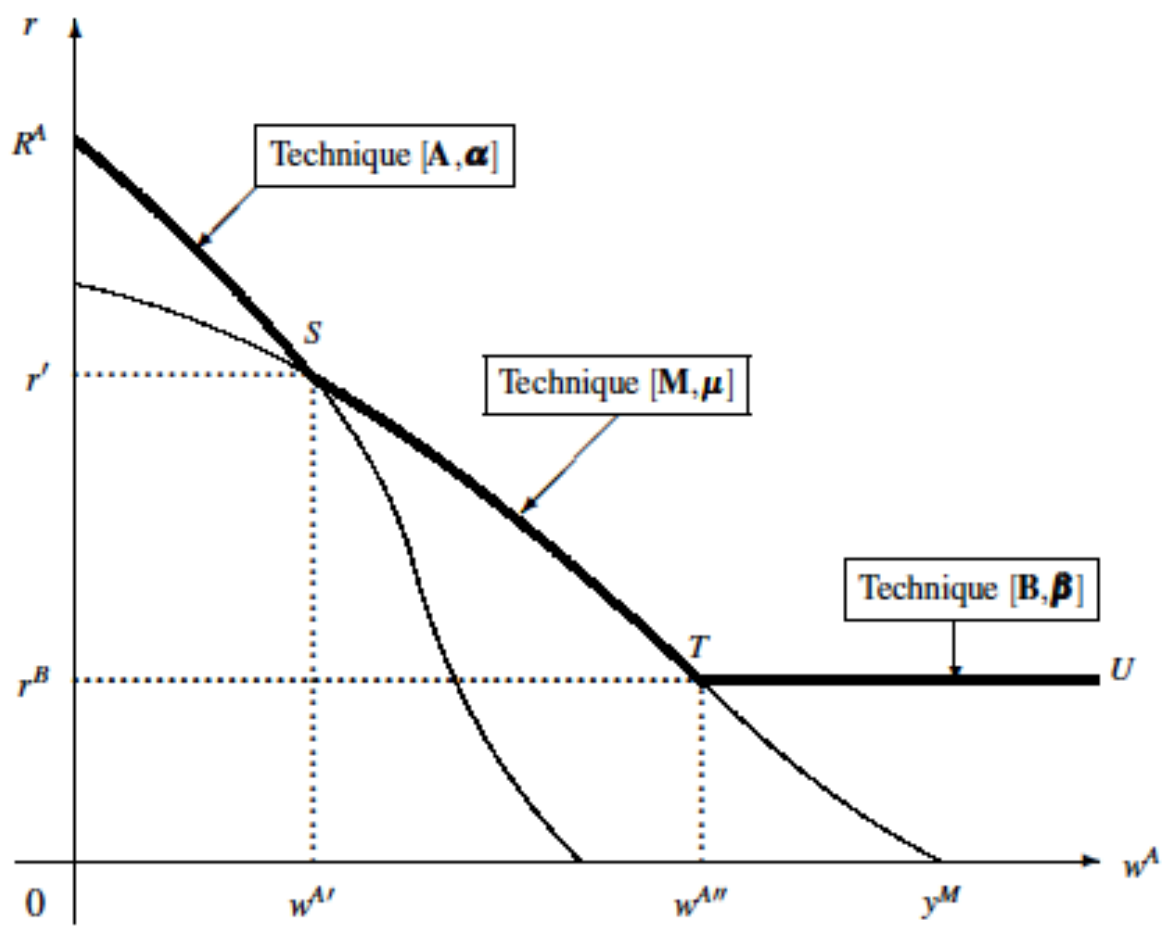

Figure 7 - Wage-profit frontier, $K$ capital goods, case I.

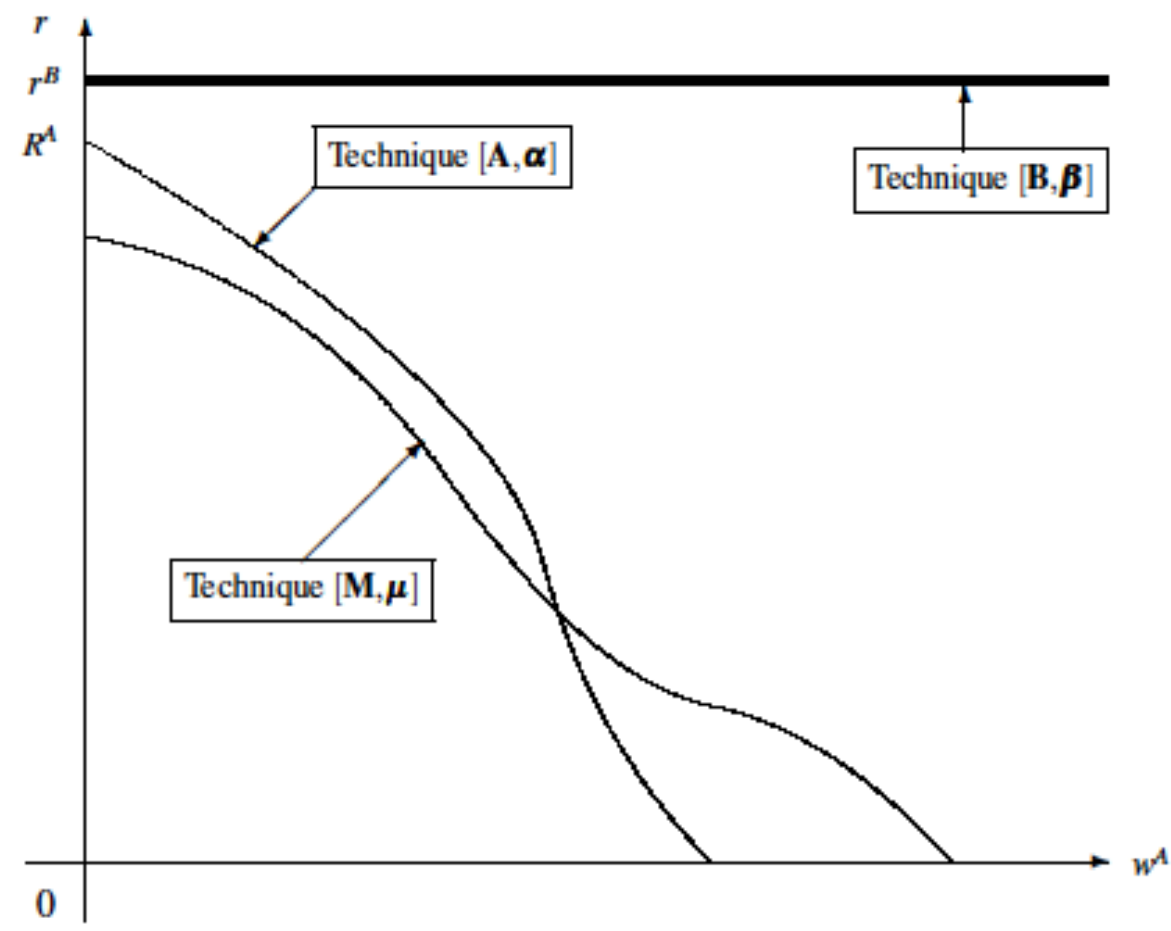

Figure 8 - Wage-profit frontier, $K$ capital goods, case II. 


\section{Concluding remarks}

According to the theory of comparative advantages, each country specializes in the production of at least one commodity and all the countries involved have gains from trade. This result - as argued in section 2 - was obtained by Ricardo under the assumption that capitalists prefer a lower rate of profit in their home country rather than investing abroad. When this assumption is dropped, different conclusions may be achieved.

The study of the case with capital mobility played an important role within the analysis of international trade from a Marxian perspective. In particular, here we have started our logical and historical reconstruction from Emmanuel's thesis about the unequal exchange between 'central' and 'peripheral' countries. As seen in section 3, according to Emmanuel, the tendency toward a uniform rate of profit - as a result of capital mobility associated with different wage rates - entails that the international relative price of the commodities produced in the central country is higher than its level if wage rates were equal. In turn, this brings about a transfer of surplus value toward the central country and its faster capital accumulation.

Emmanuel's point was originally based on Marx's mechanism of transformation of values into prices of production. Then, Gibson reformulated it using the Sraffian theory of prices (section 4). Although Gibson did not grasp this result, his analysis shows the possibility that, given the physical wage levels in both the countries, capitalists maximize the rate of profit of their investment by localizing production in one of the two countries only.

The possibility of exclusion from trade - or 'desertification' - due to a lower rate of remuneration of capital was then considered by Brewer and Parrinello. However, as we have seen in sections 5 and 6, these analyses are based on special assumptions: either production with unassisted labour, in the case of Brewer, or one capital good only, as in Parrinello's model. Here we provide a generalization of Parrinello's results for a model with any number of commodities and capital goods.

In particular, referring to a standard, general model, we have confirmed (section 7) that exclusion from trade and desertification of production are theoretically possible. Clearly, this does not mean that the production levels of an economic system will actually fall to zero. If the conditions for theoretical desertification occurred, then increasing unemployment and disequilibrium of the trade balance would force the system to drastic measures: wages will probably drop and restriction on the mobility of capital will be possibly adopted. Nonetheless, further research is needed on these issues.

\section{References}

Aspromourgos, T. (2008), The Science of Wealth: Adam Smith and the Framing of Political Economy, New York, Routledge.

Brewer, A. (1985), Trade with Fixed Real Wages and Mobile Capital, Journal of International Economics, 18: 177-86. 
Brewer, A. (1990), Marxist Theories of Imperialism. A Critical Survey, Second edition, London and New York, Routledge.

Emmanuel, A. (1972), Unequal Exchange: A Study of the Imperialism of Trade, New York, Monthly Review Press.

Gibson, B. (1980), Unequal Exchange, Theoretical Issues and Empirical Findings, Review of Radical Political Economy, 12(3): 15-35.

Kurz, H. D., and Salvadori, N. (1995), Theory of Production. A Long-Period Analysis, Cambridge, Cambridge University Press.

Montani, G. (2008), L'Economia Politica dell'Integrazione Europea, Torino, UTET.

Parrinello, S. (1970), Introduzione ad una Teoria Neoricardiana del Commercio Internazionale, Studi Economici, 25(2): 267-321.

Parrinello, S. (1973), Distribuzione, Sviluppo e Commercio Internazionale, Economia Internazionale, 26(2): 197-229.

Parrinello, S. (1988), "On Foreign Trade” and the Ricardian Model of Trade, Journal of Post Keynesian Economics, 10(4): 585-601.

Parrinello, S. (2002), The "institutional factor" in the theory of international trade: new vs. old trade theories, in Boehm, S., Gehrke, C., Kurz, H. D., and Sturn, R. (eds), Is There Progress in Economics? Knowledge, Truth and the History of Economic Thought, Cheltenham, Edward Elgar.

Parrinello, S. (2010), The Notion of National Competitiveness in a Global Economy, in Vint, J., Metcalfe, J. S., Kurz, H. D., Salvadori, N., and Samuelson, P. A. (eds), Economic Theory and Economic Thought. Essays in Honour of Ian Steedman, London and New York, Routledge.

Ricardo, D. (1817), On the Principles of Political Economy and Taxation, in Ricardo, D. (1951), The Works and Correspondence of David Ricardo, Volume I, edited by P. Sraffa with the collaboration of M.H. Dobb, Cambridge, Cambridge University Press.

Smith, A. (1776), The Wealth of Nations, in Smith, A. (1976), The Glasgow Edition of the Works and Correspondence of Adam Smith, Volumes 2a-2b, Oxford, Oxford University Press.

Sraffa, P. (1960), Production of Commodities by Means of Commodities, Cambridge, Cambridge University Press.

Vasudevan, R. (2012), Terms of Trade, Competitive Advantage, and Trade Patterns, Review of Political Economy, 24(2): 183-202. 


\section{Author contact information:}

Enrico Bellino

DISES, Catholic University of the Sacred Heart.

29100 Piacenza - (Italy)

enrico.bellino@unicatt.it

\section{Saverio M. Fratini}

Department of Economics, Roma Tre University. 00145 Rome - (Italy)

saveriomaria.fratini@uniroma3.it 